distillate of many years of first hand experience and innovation. It is a superb book and it will certainly be the constant companion of many scientists of quite varied interests. The nature and some of the theory of the use of cellulose ion exchangers is followed by a complete, practical description of all the steps in the use of ion exchange chromatography. The attention to detail is admirable. This is a book to be read and re-read. The publishers would do well to re-issue this book by Peterson as a paperback in the most inexpensive format possible, so that it may cheerfully be left on the laboratory bench and used continually as a practical manual. SydneY SHALL

\section{Molecular Concepts}

Cell Biology. By E. J. Ambrose and Dorothy Easty. Pp. $\mathrm{x}+500$. (Nelson : London, October 1970.) 75s.

Probably the most dramatic advance in biology over the last two decades has been the elucidation of the genetic code, an achievement based largely on combined biochemical and genetic studies of bacteria and their viruses. We now not only have a good idea of how genetic information is passed on to the next generation, but also of how the translation of nucleic acid into protein is achieved and controlled. Although there are still large gaps in our knowledge, we are beginning to understand the structure and function of some cell components in terms of the physical and chemical rules which underlie the properties of all living matter. Not surprisingly our understanding does not go very far. Molecular biology has not yet provided an alternative to the quasivitalist image presented by the eukaryotic cell, a unit of protoplasm containing a mysterious range of organelles whose activities we can describe but are unable to integrate into a molecular concept of the total cell.

The next generation of biologists will have to take molecular biology to this level. The appearance of an introductory textbook in this area is therefore very timely. Cell Biology, an immensely readable book, was written with the undergraduate in mind. It opens with good introductory chapters on basic physical, chemical and biological concepts for the novitiate in molecular biology. There follows an account of the structure and function of the eukaryotic nucleus. The authors draw heavily on knowledge derived from microbial studies in this and in the next section, which deal with the mechanism of protein synthesis. An account of mitochondria, chloroplasts and membranes follows, showing how their structure is important for the physiological part they play in the cell. The next sections present the cell as a self-replicating unit (growth, mitosis and genetics), and as a dynamic system (cellu- lar movement and embryology). Because the molecular controls operating in these processes are not properly understood, the authors give a survey of the working hypotheses on which current research in these areas is based.

The book covers an enormous field, ranging from models of tRNA structure to metazoan gastrulation, covering in passing the major catabolic and biosynthetic pathways and a host of other topics. As a result, some themes are given but a brief mention and, although the authors have managed to integrate the different areas satisfactorily, they cannot, of course, explore all the implications of the ideas presented. It is, therefore, vitally important that the reader is given an adequate introduction to the literature. This Ambrose and Easty sometimes fail to do, as in the case of the hypothesis proposed by Britten and Davidson to account for the regulation of gene expression in higher organisms. The hypothesis bears a relation to the operon model for gene regulation in bacteria. It is, however, considerably more complex, there being more components and more types of interaction postulated than in the bacterial model. Nevertheless the account of this theory is exceedingly brief, being reduced to the names and functions of the proposed components of the system. The reader will be disappointed to find no relevant reference to Britten and Davidson at the end of the chapter.

Cross-referencing is particularly important in a text as broad as this. Inevitably some omissions do arise, and for example the circularity of the Escherichia coli linkage map (chapter 10) is not related to the circularity of its DNA molecule (chapter 3), but on the whole the crossreferences are good.

The book is well laid out and copiously illustrated, with plenty of diagrams to amplify the text. These, together with a large number of clear and apt micrographs, a relaxed style and a good index, make the book a useful addition to the student's bookshelf.

J. G. ScAIfE

\section{Breeding for Research}

Reproduction and Breeding Techniques for Laboratory Animals. Edited by E. S. E. Hafez. Pp. ix $+375+46$ plates. (Lea and Febiger: Philadelphia. Distributed in the UK by Baillière, Tindall and Cassell, November 1970.) 210s.

THIS book, which has contributions from twenty-one British and American authors, is aimed at students of reproduction in agriculture, veterinary medicine, zoology and the biomedical sciences, and should be of value to senior animal technicians and research investigators using a species for the first time. It should also prove useful to animal-house curators and some of the more advanced commercial laboratory animal breeders.
The first section deals with comparative aspects of reproduction, and contains chapters on endocrinology, the male and female reproductive organs, semen, sexual cycles, copulatory behaviour, fertilization, cleavage and implantation, gestation and prenatal development and maternal and infant behaviour. Species differences are stressed at all times, and many of the data are gathered into tabular form.

The second section, "Breeding Techniques", deals with nine separate species or groups of laboratory animals, giving details of reproductive physiology, behaviour and anatomy and breeding methods, including brief husbandry details and techniques such as artificial insemination and ovum transfer. These chapters are generally successful in elaborating on the information given in the previous section, and there is surprisingly little repetition.

The subject "Reproduction and Breeding Techniques" is covered fairly well, though a chapter on the comparative genetics of reproduction would have been useful. Some of the statements on genetic aspects of stock improvement are misleading. Fig. 16-4, for example, implies that inbreeding means brother $\times$ sister or parent offspring mating, and that line breeding is a distinct breeding method. In fact, inbreeding occurs if any related individuals are mated, and line breeding is a mild form of inbreeding. There are several errors and incorrect statements, for example, "some well controlled and characterized inbred strains (of rats) are being produced in a limited number of laboratories for specific projects but are not available commercially". Yet, Animals for Research 1968 (which is cited as a general reference at the end of the book) lists nine distinct inbred strains and three F1 hybrids available from eleven commercial breeders in the United States, and there are at least fifty inbred strains of rat available in the world.

Some serious omissions also occur in the references, though no attempt has been made to give a comprehensive bibliography. Reference should certainly have been made, however, to $\mathrm{E}$. $\mathrm{L}$. Green's Biology of the Laboratory Mouse (McGraw-Hill, 1966); R. Rugh's The Mouse-Its Reproduction and Development (Burgess Publishing Co., 1968); and Roy Robinson's Genetics of the Norway Rat (Pergamon Press, 1965).

Finally, one unfortunate omission occurs in the table showing chemical methods of euthanasia. No mention is made of the use of carbon dioxide, yet the Universities Federation for Animal Welfare (UFAW) in its booklet Humane Killing of Animals (UFAW, 1967) "... recommends carbon dioxide as the most suitable chemical for the euthanasia of small animals".

In spite of these relatively minor criticisms, this book will be a useful and welcome addition to the literature on laboratory animals. MichaEL Festing 